\title{
AC 2012-4226: EMPHASIZING CORE CALCULUS CONCEPTS USING BIOMEDICAL APPLICATIONS TO ENGAGE, MENTOR, AND RETAIN STEM STUDENTS
}

\section{Dr. John D. DesJardins, Clemson University}

John DesJardins received his Ph.D. in bioengineering from Clemson University in Dec. 2006 and has worked for more than 15 years as a biomechanical research engineer. He has co-authored more than 150 peer-reviewed journal and conference publications in the areas of biomechanics, biomaterials tribology and mechanical testing, and is the director of the Laboratory of Orthopaedic Design and Engineering at Clemson University. He currently leads or participates in many multi-disciplinary research teams on projects funded through NASA, DoD, DoT, NSF, biomedical industry, and other region non-profit foundations. As an Assistant Professor, he is the primary instructor for the senior capstone design courses, where he has lead small teams to develop innovative biomedical devices. He regularly interacts with local biomedical industry representatives that are interested in undergraduate education and outreach. He is the Founder and Current Director of the undergraduate bioengineering study abroad programs.

Dr. Ellen Breazel, Clemson University

Dr. Marilyn Reba, Clemson University

Dr. Irina Viktorova, Clemson University

Jonathan Bradford Matheny, Clemson University

Dr. Taufiquar R. Khan

(C)American Society for Engineering Education, 2012 


\title{
Emphasizing Core Calculus Concepts Using Biomedical Applications to Engage, Mentor and Retain STEM Students
}

\begin{abstract}
With an increasing demand for biomedical and bioengineering professionals in the coming decades, educators are tasked with readying a greater number of STEM students who are able to apply mathematical concepts to critical health care decisions. In this work, we have developed a series of for-credit, applied learning modules that are being given in parallel to the freshman and sophomore calculus curriculum. These modules use creative inquiry and applied learning experiences to connect mathematical concepts with bioengineering and medical applications. We hypothesize that exposure and participation in the applied learning experiences outside of standard mathematics classes, will improve the students' performance and perceived appreciation for their math curriculum.
\end{abstract}

The four module series is offered over a 2 year period to groups of up to 25 students, and emphasize mathematics and statistics relevant to four biomedical research areas 1) orthopaedics, 2) infectious diseases, 3) heat propagation in the human body, and 4) mammography and radiology. In class activities are complimented with biomedical facility field trips, greater access to professors and tutors outside of class, and audio-video tutorials. In this paper, the methods and results of module one are presented (orthopaedics, recently completed in the Fall 2011 semester with 3 students participating). Assessment of project outcomes consists of a formative and summative evaluation. When complete, pre and post surveys, follow-up surveys, and exit interviews will be used to assess the student's satisfaction with the modules, usefulness of the field-trips, and to gage student understanding of uses of mathematics in STEM fields. In addition, student's performance in current and future math courses and retention in STEM majors are being monitored from participation in modules until graduation.

This scalable project utilizes a diverse set of faculty from the math and bioengineering departments. The project value to STEM goals are found in, 1) convincing students through applied learning experiences that mathematics is an important component of any research plan and indispensable to their career success, and (2) ensuring that these students do not falter in calculus and abandon their STEM goals. Outreach modules for K-12 are also being developed as part of student participation. This paper presents our developed methods and initial findings with the hopes of inspiring other institutions to adopt similar applied learning experiences for their STEM students.

\section{Introduction}

Research in science and engineering is increasingly reliant on mathematical and statistical tools. The NSF has argued that to build a competitive international workforce in STEM fields, colleges and universities must inspire a greater number of students to learn a greater amount of mathematics and statistics [1]. The growing field of biomedical science and bioengineering challenges students to make critical decisions about people's lives and diseases, and demands a 
deep understanding of the quantitative complexity both of the biological system and of the decision-making process. Biomedical science and bioengineering as well as other medical majors are among the most popular fields for college graduates today. For students to succeed in such fields, mathematicians must do a better job of explaining to students how mathematical concepts and quantitative analysis can be applied in biomedicine and why it is important to succeed in the undergraduate mathematics curriculum. The challenge is to catch the attention of STEM students by offering early applied learning experiences that engage them with the application of mathematics and statistics in professional practice and applied learning applications.

At a freshman or sophomore level, it can be a challenge to connect mathematical concepts with bioengineering and medical applications, and to challenge the students' view of what mathematics can offer them. Many incoming freshmen declare a STEM major, but know little about their declared field or about how Calculus can be applied to a particular STEM field. Often teachers are faced with the student-framed question, "When am I ever going to use this?" Students can be insufficiently motivated to work consistently in their Calculus courses in pursuit of undefined educational or life-long goals. Consequently, they can under achieve in these fundamental STEM courses and possibly leave their STEM field. Too often, this STEM-attrition scenario disproportionally involves women, underserved minorities, first-generation college students, and community-college transfer students [2]. They may be less knowledgeable about their career options and less prepared for the rigors and pace of college mathematics. The authors believe that one benefit of using medical applications in applied learning environments is their appeal to a broad range of students, as most everyone has personal experiences with health issues.

Past research has focused on the importance of success in the first college math course and its correlation with success in engineering, and other STEM fields [3]. Calculus is particularly noted to be a stumbling block [4]. Since 2006, the efforts by the authors' home institution have been heavily invested in classroom redesign of freshman Calculus courses. All sections of Calculus I adopted a variation of the SCALE-UP active-learning instructional model which includes short lectures, student collaboration at round tables, and graded group activities [5]. These changes are consistent with research emerging from the Calculus Reform Movement showing that the longer you lecture the less students retain, as well as with recommendations to include small-group or collaborative classroom learning activities [6]. Initial results with this revised curriculum have been very promising, with 2008 results showing a nearly 50\% reduction in the DFW (students receiving a $\mathrm{D}, \mathrm{F}$, or withdrawing from the course) rate compared with Fall 2005 measures. Despite these efforts however, approximately $20 \%$ of students continue to earn a DFW, and either had to repeat the course or abandon their STEM career goals. Clearly, more innovative concepts in instruction should be considered to decrease this rate of student loss.

Recent work in by the authors' home department has included the introduction of Tablet PCs into several sections of Freshman Math courses in 2006. Student perceptions, behavior and performance (especially of weaker students) were shown to improve [7]. With this the department created a dedicated technology classroom that included workstations with highpowered software, multiple projection capability, Smart screens, as well as Tablet PCs. The ability to view multiple applications such as video, lecture notes, and worksheets simultaneously was shown to provide the students with increased understanding of their material. 
Another challenge to innovative and supplemental instruction is developing a learning opportunity that can fit it into a student's schedule and course-credit structure, and to insure that all participants (faculty and students both) receive merit-based credit for participation. At the authors' home institution, "Creative Inquiry" is a program course structure, which strives to engage students in the process of learning and discovering through faculty-mentored research and outreach activities across multi-disciplinary departments. Students that participate in these Creative Inquiry classes have been shown to learn and to think in new ways, learn non-class skills designed toward their interests, enhance their academic performance in other classes, improve their satisfaction with their learning environment, and improve their relationships with faculty. In addition, instructors that teach Creative Inquiry classes develop mentoring relationships with students, have the opportunity to develop courses toward a specific area of interest that spans several departments, and rejuvenate and improve their teaching in other courses. At the authors' home institution, the university provides monetary support for courses taught under the Creative Inquiry framework, and since its conception in 2005 the university has offered a total of 275 Creative Inquiry courses 12 of which are from the Mathematical Sciences department.

In this paper, the authors describe the initial results from a 2 year NSF funded collaborative project between faculty from the Mathematical Sciences and Bioengineering departments that combines inspiration in Biomedicine with retention in Calculus, directed at freshman and sophomore students. This paper describes the initial results from Module 1: Orthopaedics and Pre-Calculus.

\section{Materials and Methods}

\section{Program Structure}

Students participated in one-hour modules where they discuss biomedical applications to their current math courses, interact with faculty and student mentors, participate in field trips, and have access to a textbook repository. The goal of this program is to have all participants engaged in the interplay of mathematical and biomedical concepts in the context of interesting applications that may help them formulate career goals while deepening their understanding. This program was designed to emphasize mathematics and statistics relevant in four biomedical areas that are directly linked to the students progression through their core calculus courses (figure 1):
Module 1 Orthopaedics, Module 2 Disease Epidemiology, Module 3 Health Hazards from Arc-flash Module 4 Mammography and Radiology 


\section{Emphasizing Core Calculus Concepts Using Biomedical Applications to Engage, Mentor and Retain STEM Students}

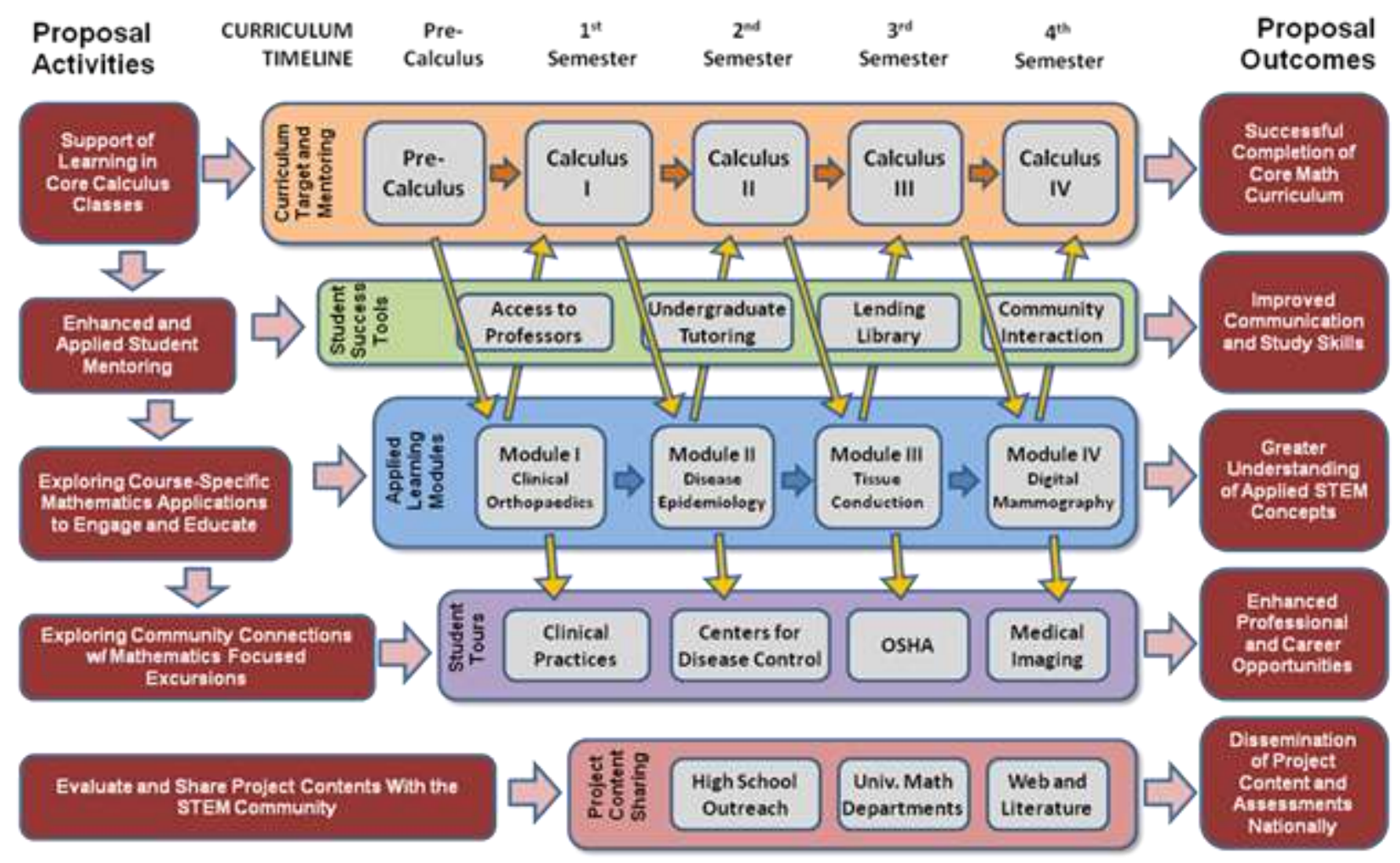

Figure 1: A summary flowchart of the program activities, modules, support materials and outcomes showing the relationship between the students' calculus curriculum and the applied learning modules that are being used to reinforce this educational content.

Students have the opportunity to enroll in one module per semester for up to four semesters. They enter modules coordinated with their current or previous math courses (whether precalculus, first semester calculus (calculus of one variable), second semester calculus (calculus of one variable II), or third semester calculus (calculus of several variables)). By presenting interesting biomedical problems as early undergraduate applied learning experiences, instructors are required to decompose a difficult mathematical problem into its simpler parts that students can manipulate. These modules are broken down into 5-7 weekly lessons of one to two hours each. The modules usually begin three to five weeks into the semester, to give students an opportunity to learn the basics in their math courses before beginning these applied-learning experiences. Students are introduced to the exciting field of study and given an interesting problem to solve, with the mathematical component structured to their level of understanding. Students work through a problem, identify what they don't fully understand and seek remedies. They are then given the opportunity to interact with their peers in group activities and their instructors, and participate in on and off campus fieldtrips. This level of communication, where students work on a problem of interest, invest in learning, and even discuss future learning for their problem of interest is impossible to achieve in large content heavy math classrooms that have little time to spare. 
In addition to these group activities, students have the opportunity to visit local professional facilities that provide the services studied in the module. These field trips are undertaken as the students have the opportunity to explore the mathematical concepts that are relevant to the applied learning experience of interest, and are used to reinforce the practical applications and empowering nature of the mathematical skills that they are acquiring in class and applying in their learning modules.

All participants receive mentoring from their active learning experience instructor and a designated advanced undergraduate mentor that works to enhance their success in their mathematics courses. All participants are matched with faculty or undergraduate-student mentors who will communicate with them both in-person and through web-based technology at various times throughout each week. Although the modules do not begin until three to five weeks into the semester (other than an introductory meeting on week 1), the mentoring begins the first week of classes.

Copies of textbooks from the core calculus courses are also available for student loan.

Participation in the modules allows students the use these textbooks for the semester the module is taken. The library consists of texts from pre-calculus, single-variable calculus, multi-variable calculus, and topic specific biomedical and statistics texts that enhance their individual learning module experience.

\section{Recruitment}

This work was conducted under institutionally approved IRB protocols and research methods. Recruitment for this program included specific attention towards women, minorities, firstgeneration college students, and community college transfers through direct advertising in the institutions WISE program (an organization for female STEM students), FIRST program (a program for students who are the first in their immediate family to attend college), PEER program (a mentoring program that includes transfer students), BRIDGE program (a specialized program for students from a local community college), and finally a pre-freshmen Summer Mathematics Excellence five-week Workshop (MEW) for underrepresented students. Recruiting efforts are focused on obtaining 25 students per module. An initial trail of this program was completed during the Fall 2011 semester using Module 1 (Orthopaedics and Pre-Calculus) of this program with 3 students participating.

\section{Module 1 Curriculum \\ Orthopaedics: Fundamentals of Pre-Calculus in Orthopaedic Medicine}

This beginning module was intended to reinforce pre-calculus curriculum based on the home institutions state pre-calculus standards. It was offered as a one credit course that was spread out over one semester and it was intended to engage the student in basic bioengineering problems requiring algebra and trigonometry, and introduce areas of study and applied mathematics that required the use of pre-calculus to effectively solve real-world problems. It reinforced scalar, algebraic and trigonometric concepts that were relevant to orthopaedics and total joint 
replacement. Students participating in this module were expected to have already taken or current be taking course content equivalent to the following university level courses:

MTHSC 103 Elementary Functions 3(2,2) Gateway course for MTHSC 106. Comprehensive treatment of functions and analytic geometry with applications including polynomial, rational, algebraic, exponential, logarithmic, and trigonometric functions. Not open to students who have received credit for MTHSC 105. To be taken Pass/Fail only. Preq: MTHSC 104 or satisfactory score on the Clemson Mathematics Placement Test.

MTHSC 104 College Algebra 3(2,2) Basic course to prepare students for subsequent courses in probability, mathematical analysis, elementary statistics, and elementary functions (precalculus).

Fundamental concepts of algebra, equations, inequalities, functions, and graphs are studied. Students who have received credit for any other mathematical sciences course will not be allowed to enroll in or receive credit for MTHSC 104. To be taken Pass/Fail only.

MTHSC 105 Precalculus 5(4,2) Extensive treatment of topics chosen to prepare students for the study of calculus. Special emphasis is given to polynomial, rational, exponential, logarithmic, and trigonometric functions and their graphs, as well as basic and analytic trigonometry. Students who have received credit for any other mathematical sciences course will not be allowed to enroll in or receive credit for MTHSC 105. To be taken Pass/Fail only.

\section{Module 1 Course Schedule}

Week 1: Orientation and Introduction to Module

(1 hour with introduction, orientation and syllabus)

Week 3: Tour of Clemson Bioengineering Department and Biomechanics Lab (pre-survey and department tour, 1 hour)

Week 4: Activity 1: Orthopaedics, Angles and Basic Trigonometry

(15 minute lecture with 45 minute applied learning activity)

Week 5: Tour of Local Orthopaedics and Sports Medicine Practice (2 hours)

Week 6: Activity 2: Anthropometry, Measurement, Percentiles and Averages (15 min lecture with 45 minute applied learning activity)

Week 7: Student K-12 Outreach Project Development (1 hours)

Week 8: Student K-12 Outreach Project Development (1 hours)

Week 9: Activity 3: Orthopaedics, Angles and Polynomials

(15 minute lecture with 45 minute applied learning activity)

Week 10: Tour of Total Joint Replacement Testing Facility (1 hour)

Week 11: Student K-12 Outreach Project Development (1 hours)

Week 12: Total Joint Replacement Motion and Kinematics (15 minute lecture with 45 minute applied learning activity)

Week 15: Student K-12 Outreach Presentations

(1 presentation and review)

Week 16: Module Review and Assessment

(1hour summary and assessment) 
Week 4 (1 Hour Applied Learning Module: Orthopaedics, Angles and Basic Trigonometry) In this module, students were given an opportunity to participate in a "life or death" project that challenged them to formulate a treatment regimen for an orthopaedic condition. This condition, known as a lower limb deformity, required the student to apply simple concepts in angle measurement and trigonometry to correct a bony anatomical deformity in a patient. This module began with in-class review of basic

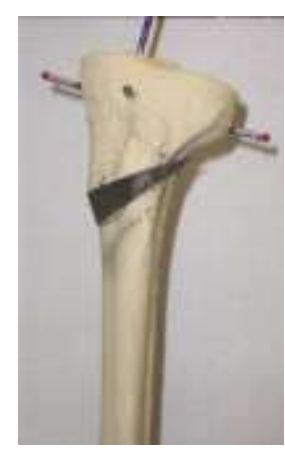

Figure 4: interactive hands-on bone models reinforce analytical calculations in this module. geometry and trigonometry and an introduction to the pathologic conditions of lower limb deformity. Students were then given a "patient's" X-rays that showed a common deformity of the lower limb (figure 2). They were then asked to calculate a tibial re-alignment treatment to correct the deformity (figure 3). Using these $\mathrm{x}$-rays, the students used simple measures of bone length, width, and angular deformity, apply basic trigonometry to "cure" the patient. The accuracy of the surgical correction was then visualized on a surgical training bones (figure 4), and a computer model of this bony system. The students were encouraged to explore a range of treatment options using these interactive models. Discussions of actual before-after surgical treatments for this condition using $\mathrm{x}$ -
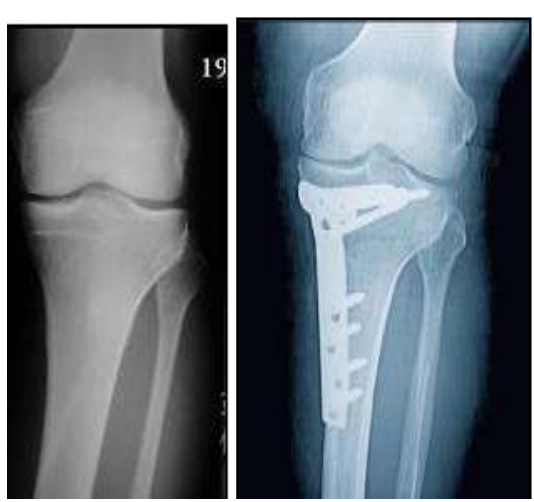

Figure 2: Bone mal-alignment and surgical correction surgery requires the application of trigonometry to solve anatomical problems.



Figure 3: Simple angular wedge models of this system can become quite complex, and force the introduction of higher order trigonometric functions and canonical applications. rays were presented. These concepts contained some of the challenges for pre-calc students and therefore the reiteration and application of these topics was intended to help strengthen their understanding.

Week 4 Outcomes: Hands-on use of rulers and protractors. Applied knowledge of scalar quantities, radians and degrees, relative and absolute angles, applied use of sines, cosines, tangent functions. Participation in Team Activity. Discussions of experimental variables. 


\section{Mathematics Applied:}

\section{Basic Trigonometric Functions}

$$
\begin{aligned}
& \sin A=\frac{\text { opposite }}{\text { hypotenuse }}=\frac{a}{c} \cdot \cos A=\frac{\text { adjacent }}{\text { hypotenuse }}=\frac{b}{c} . \\
& \tan A=\frac{\text { opposite }}{\text { adjacent }}=\frac{a}{b}=\frac{\sin A}{\cos A} .
\end{aligned}
$$

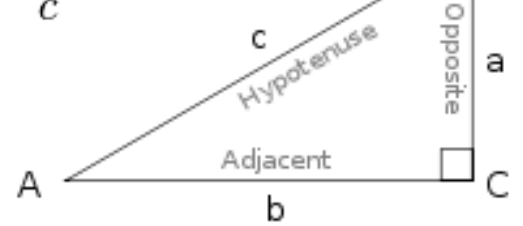

\section{Assessment}

Assessment focused on how this approach, combined with introducing the students to mathematical skills they will need to learn (in some cases next semester), enabled the student to more confidently approach an entire mathematical concept in the context of applied learning.

Formative evaluations began with the first teaching of Module 1, and will continue with every implementation of a module. External evaluations are to take place midway through the 2 year program and again at the end of the program. Both evaluations are designed to gather information in order to answer the following questions:

- Goal 1: Does participation in these activity based learning modules improve student knowledge in current math courses?

- Goal 2: Do these modules improve student performance in current math courses?

- Goal 3: Does participation in these activity based learning modules improve student performance in future math courses?

- Goal 4: Does the implementation of activity based learning using medical applications affect the retention in STEM majors?

- Goal 5: Do applied learning modules, such as the ones proposed, have disseminative potential to high-school, community college and other 4 year institutions with an interest in adopting this approach to enhance early undergraduate applied learning?

Internal Evaluation

The formative evaluation consists of pre and post exams aimed at testing the basic math skills utilized in the module. Student performance and major changes are monitored in semesters following module participation until graduation. Pre and post surveys are conducted focusing on the improvements needed in implementation.

Pre-survey

Pre-surveys were administered in the first week of each module semester (during the introductory meeting) by the module instructor. These surveys gathered information about the demographics of the students registered for the module. In addition, the preliminary surveys gather information on the student's math background and initial perception of uses of mathematics in STEM fields. Instructors are then able to gage the module according to the information obtained.

Post-survey

Post-surveys were administered at the last meeting of the module during the semester by the module instructor. These surveys gathered information on the students' satisfaction of the instructors and the material taught. In addition, these surveys gaged the students' perception of 
how much their participation in the modules helped their performance in their math and biology courses. The information obtained from these surveys was used to make improvements to the modules for future implementation.

Follow-up Surveys

After a student has completed at least a semester of study after the participation in a module, participants will complete an on-line follow up survey to gage the retention, and usefulness of the knowledge obtained from the modules in the subsequent semesters. Students are asked to participate in these follow-up surveys every semester until graduation.

Student Performance and Retention in CES majors

In the institutions core calculus courses, semester and final exams are recorded for each student. Of this program comparisons will be made for participants in these modules versus comparable students that did not participate for the semester the student takes the module as well as subsequent semesters. In addition, the participating students will be monitored for change in majors to a major outside of STEM until graduation. Comparisons will be made on proportion of participating students that switch majors (to outside STEM) to a comparable group of students that did not participate in the modules. Comparable students will be obtained via quantitative measures such as math SAT score, previous exam scores, math placement scores etc. These student control groups will be chosen with assistance from an in house statistician, and the identity of these participants will be kept blind from the participating instructors and departments until the conclusion of each semester and module.

\section{Exit Interviews}

Interviews with all participating students were conducted, with a project member or undergraduate not associated with the module in question, at the end of the semester the module is implemented. The interviews were intended to gather information from students about the implementation of the modules and any concerns or improvement suggestions the students may have. Information obtained from these interviews will be used to improve the modules for future implementations.

\section{Results}

The first offering of this program in Fall 2011(Module 1: Orthopaedics and Pre-Calculus) was an introductory module, and was used to troubleshoot the program infrastructure and activity development, and establish the mentoring and tutoring infrastructure. Three students participated, and of these students, there was one African American female, one Caucasian female, and one Caucasian male. In addition, two first-year $\mathrm{PhD}$ students who were active in minority education volunteered to mentor these students and serve as additional TA's for the course. They participated in all components of the module and were assisted in compiling the post-survey results.

Two months during the summer were used to develop the module activities, and a per-hour undergraduate assistant in bioengineering was employed to assist in developing, troubleshooting and practicing the modules for clarity and impact. Module activities were largely distilled from the ongoing research projects of one of the authors within the bioengineering department, and as 
such the hands-on nature of the activities was innately driven by the need to collect data that would be of relevance to the research question at hand. In addition, examples of the clinical usefulness resulting importance of the activity and data collected could be clearly discussed with the student, because most of the activities were tied to a research question that was both timely and relevant to a clinical research question, and there was adequate expertise within the laboratory environment to give the student a clear understanding of scope of work.

The student field trip was to a local orthopaedic surgeon's practice, who volunteered to discuss the importance of geometry and trigonometry in their daily orthopaedic practice. This surgeon spent an hour given real-life examples of patient cases that required the use of these mathematical principles to arrive at accurate clinical diagnoses, and also discussed more advanced uses of these principles in the design and use of orthopaedic fracture fixation devices.

The in class activities were separated with tours of the bioengineering department and tours of specific research laboratories that were relevant to upcoming in class activities. This was intended to give the student added context for the activities importance and relevance, as well as to give the student a greater understanding of other research that was being conducted within these research areas. A secondary goal was to also introduce them to more academic and research opportunities within the department to expand their educational community.

All activities in Module 1 were successfully developed and implemented over the semester, with high student satisfaction in these activities. In response to the post-survey questions (TA's included):

"Which Orthopaedic Lab-Based Activity did you enjoy the most, and why?

Answers received were:

- "adding wedge to properly re-align leg hands on, I was able to immediately see results"

- "creating our own [K-12 outreach activity]. It was cool to see how the things we learned are applied to real-life situations"

- "I enjoyed the joint replacement [kinematic activity] best because I could partially relate to it. It opened my eyes as to why some people walk a certain way (knock-kneed, bow-legged, etc)"

- "I thought it was great to go on the field trip to the orthopaedic center"

In addition student reaction to the Module overall was overwhelmingly positive, with responses to the post-survey questions of:

What did you think about the course in general?

Yielding answers of:

- "It was a lot of fun and wasn't too hard and was nice to have a class that wasn't stressful"

- "I think this course was great. Math, especially Calculus, often eludes people due to their lack of awareness of real-world applications. I think this course served well to start to bridge the gap."'

- "I love this course and would recommend this course to everyone!!" 
- "I thought it was cool. I've never applied calculus, trigonometry, or any type of math to real life. This class did that for me, which makes me want to learn even more now. The activities we did were really creative also, so I enjoyed them."

- "It covered a lot of interesting material that applies to actual life"

Finally in response to the question:

How likely is it that you would recommend this Creative Inquiry class to a friend? 1 - Very Unlikely $\quad 2$-Somewhat Unlikely

3 - Neutral $\quad 4$-Somewhat Likely 5 -Very Likely

The module received a 5.0+/-0.0 (5 out of 5 from all 5 respondents).

Questions from the Module 1 exit interview are listed below, and the results from the 3 undergraduate students that participated in the course are listed in Table 1.

Exit Interview Items:

1. Do you believe this course motivated/helped improve your experience in your Calculus classes? Explain.

2. What part(s) of the module implementation (teaching, worksheets, communication, field trip, etc.) do you think were the best and should be kept? Explain.

3. What part(s) of the module implementation (teaching, worksheets, communication, field trip, etc.) do you think were the worst and should be deleted? Explain.

4. Do you have general suggestions for improvement of the module? Explain.

5. Please select the answer that best describes the amount of times you attended tutoring or used an online help tool.
A. Never
B. A few times
C. Frequently
D. Very Frequently

Results from the long-term follow-up data will be available until the end of the Spring 2012 semester. The first offering of Module 2 and Module 3 are currently underway. Module 2 is entitled: Math Applications in Disease Epidemiology - Modeling the spread of contagious diseases, with 31 students, and Module 4 is entitled: Math Applications in Health Hazards from Electric Current - Issues Related to Human Tissue and Electricity, with 14 students. The results of these modules will add further sets of data to the overall program.

\section{Discussion}

A key component of this work is the use of multi-departmental (or multi-disciplinary) collaborations to arrive at a greater academic impact. In the case of the authors host institution, collaborative educational activities between the department of Mathematical Sciences and Bioengineering were originally sparked by a creative inquiry project to that focused on bringing undergraduate students and faculty from both departments together to explore research areas and ideas that bridge the disciplines and require the expertise of both fields to address biomedical and applied mathematical concepts. Over 2 years' time, over 20 cross-disciplinary faculty lectures were presented, over 20 undergraduates took the course for credit, and 4 student groups conducted multi-disciplinary research under this initiative. The work presented here is a further extension of this collaboration, and offers a further bridge between the two departments. 


\begin{tabular}{|c|c|c|c|c|c|}
\hline & Question 1 & Question 2 & Question 3 & Question 4 & Question 5 \\
\hline $\begin{array}{l}\text { Student } \\
1\end{array}$ & $\begin{array}{l}\text { Yes. The real life } \\
\text { applications made learning } \\
\text { and understanding calculus } \\
\text { a lot easier. It gave the } \\
\text { calculus material a little } \\
\text { more purpose, also. Help } \\
\text { was constantly offered } \\
\text { which motivated me to } \\
\text { succeed. }\end{array}$ & $\begin{array}{l}\text { I think the teaching and } \\
\text { the worksheets were very } \\
\text { helpful. They contained } \\
\text { applications, as well as } \\
\text { step-by-step guides on } \\
\text { how to complete various } \\
\text { types of calculus } \\
\text { problems. The mini in- } \\
\text { class activities were } \\
\text { helpful, too. }\end{array}$ & $\begin{array}{l}\text { I wasn't able to } \\
\text { make it to the field } \\
\text { trip so I cannot } \\
\text { comment about } \\
\text { that portion. I } \\
\text { thought the course } \\
\text { overall was very } \\
\text { well executed. }\end{array}$ & $\begin{array}{l}\text { Not that this } \\
\text { was of your } \\
\text { power, but a } \\
\text { course with } \\
\text { more students } \\
\text { involved may } \\
\text { have been } \\
\text { more effective. }\end{array}$ & $\bar{A}$ \\
\hline $\begin{array}{l}\text { Student } \\
2\end{array}$ & $\begin{array}{l}\text { I do believe this course } \\
\text { improved my overall } \\
\text { Calculus experience. The } \\
\text { reason behind my } \\
\text { improvement was the fact } \\
\text { that I was shown one way } \\
\text { how this could apply to life } \\
\text { outside of the classroom. }\end{array}$ & $\begin{array}{l}\text { The field trip was the } \\
\text { best part in my opinion, } \\
\text { it got us out of the } \\
\text { classroom and } \\
\text { introduced us to the } \\
\text { application of what we } \\
\text { were learning. }\end{array}$ & $\begin{array}{l}\text { The worksheets } \\
\text { were my least } \\
\text { favorite. The } \\
\text { reminded me more } \\
\text { of the learning } \\
\text { activities done in a } \\
\text { normal setting and } \\
\text { took away from the } \\
\text { Creative Inquiry } \\
\text { experience. }\end{array}$ & $\begin{array}{l}\text { I do not have } \\
\text { any } \\
\text { suggestions for } \\
\text { the course, and } \\
\text { I enjoyed my } \\
\text { time enrolled } \\
\text { in it. }\end{array}$ & B \\
\hline $\begin{array}{l}\text { Student } \\
3\end{array}$ & $\begin{array}{l}\text { I really think that the extra } \\
\text { help would be very helpful } \\
\text { to someone who was just } \\
\text { beginning calculus or in a } \\
\text { new calculus class, but } \\
\text { since I took Calc } 1 \text { and } \\
\text { Calc } 2 \text { in high school I'm } \\
\text { rather familiar with it. The } \\
\text { extra help wasn't needed } \\
\text { for me but I do think it } \\
\text { would be very nice for } \\
\text { someone who isn't familiar } \\
\text { with the class they're in. }\end{array}$ & $\begin{array}{l}\text { I really did enjoy the } \\
\text { field trip and speaking } \\
\text { with the orthopedic } \\
\text { surgeon. I also thought } \\
\text { doing the hands on } \\
\text { activities, such as } \\
\text { applying the wedge in the } \\
\text { knee bone, was really } \\
\text { amazing. That should be } \\
\text { in there for sure. }\end{array}$ & $\begin{array}{l}\text { Even though the } \\
\text { worksheets were } \\
\text { needed, I wasn't a } \\
\text { big fan of them. } \\
\text { They seemed to not } \\
\text { be very helpful. }\end{array}$ & $\begin{array}{l}\text { The worksheets } \\
\text { weren't very } \\
\text { fun even } \\
\text { though the } \\
\text { information } \\
\text { that we were } \\
\text { relearning was } \\
\text { useful, maybe } \\
\text { that section of } \\
\text { the class can } \\
\text { be cut a little } \\
\text { shorter. }\end{array}$ & A \\
\hline
\end{tabular}

Table 1: Module 1 exit interview results from the 3 undergraduate students that participated in the course are listed in Table 1.

Dissemination of this work is a key component of this project. As is the case with the current work, the results of each module will be assembled for conference dissemination. A project website has been developed that can be used by participating students, and this site will be opened to other institutions to assist in implementing similar programs at their high school, college or university. For each module the website will house video of lectures, worksheets, podcasts, pictures from field trips, and more. In addition to the module information the website will have the results of all pre and post surveys, follow-up surveys, reports of assessment from each evaluation period, and a final report from the entire 2 year project.

Long-term plans for this work include expansion of the modules to include Data Mining, Genetic Sequencing, Nano-Medicine, BioFluid Dynamics, and Network simulation for the "Smart Grid Technologies." Dissemination would hope to expand the program into other institutions. An external evaluation model will be used to assess the implementation of the program, and the final 
report will be shared and published through the project website and by the project members at various conferences.

The goal of engaging, mentoring and retaining STEM students can be empty rhetoric without a lot of creative thinking. The project presented here stands on the shoulders of creative projects in the Mathematics and Bioengineering departments that involve new instructional methodology, new uses of technology, and experience in creative inquiry connecting undergraduates with experts in various fields in the university and industry. The project also stands on the shoulders of the host institution's efforts at developing undergraduate scholarship in the Creative Inquiry program. The program strategy and plan involves faculty members who have participated in projects like the ones described above and who have experience in the development of appliedlearning experiences in Biomedicine that involve quantitative issues at the level of the students' current math courses. The evaluation of the project makes use of the extensive database on individual student performance maintained by the Mathematics Department. The project management team consisted of faculty members from Mathematical Sciences and Bioengineering who were enthusiastic about working together to recruit students for this project, implement the research experiences, accompany students on trips to labs in medicine and industry, mentor the students in their mathematics courses, and evaluate the project.

\section{Acknowledgements}

The authors wish to thank Clemson University supporting the efforts of the Creative Inquiry program.

\section{References}

1. National Science Foundation. Proactive Recruitment in Science and Mathematics, Synopsis of the PRISM program. Solicitation 09-596.

2. Schwartz, M., Hazari, Z, \& Sadler, P. (2008). Divergent Voices: Views from teachers and professors on precollege factors that influence college science success. Science Educator, 17(1), 18-35.

3. Seymour, E. \& Hewitt. N. Talking about leaving: Why undergraduates leave the sciences. Westview Press, Boulder, CO, 1997.

4. Ohland, M.W. \& Sill, B. Identifying and removing a Calculus pre-requisite as a bottleneck in Clemson's general engineering curriculum.

5. Beichner, R. Student-Centered Activities for Large-Enrollment University Physics (SCALE-UP), Principal Investigator, NSF Award 9981107.

6. National Science Board. Undergraduate Science, Mathematics and Engineering Education: Role for the National Science Foundation and Recommendations for Action by Other Sectors to Strengthen Collegiate Education and Pursue Excellence in the Next Generation of U.S. Leadership in Science and Technology, Report of the Task Committee on Undergraduate Science and Engineering Education, Neal, I-I., Chair, Washington DC.

7. Reba, M., and B. Weaver. (2007)"Tablet PC-Enabled Active Learning in Mathematics: A First Study." In Proceedings of the International Workshop on Pen-Based Learning Technologies (IEEE), 10-16. 